\title{
Real - Time Operation Strategy and Strategy Evaluation of Photovoltaic Charging Station Considering Transmission Loss and Charging Demand
}

\author{
Hongyi Chen ${ }^{\mathrm{a}}$, Mingyang Zhang ${ }^{\mathrm{b}}$, Guangzhao Yang ${ }^{\mathrm{c}}$, Weicong Lin ${ }^{\mathrm{d}}$, and Xinyue Wang
}

North China Electric Power University, No.2. Beinong Road. Changpin District. Beijing 102206, P. R. China

a18367959057@163.com, bflank830@sina.com, cyangguangzhao4real@163.com, d787094758@qq.com, e13125538865@163.com

Keywords: Time-of-Use electricity price, Transmission loss, Feasible domain model, Analytic hierarchy process, Fuzzy comprehensive evaluation method.

\begin{abstract}
Efficient and economical operation strategy of car PV charging station helps to realize the large-scale use of electric vehicles. Based on the consideration of time-of-use electricity price and transmission loss, this paper proposes a new strategy for the operation of photovoltaic vehicle charging stations and analyzes the strategy by fuzzy decision method based on AHP. The evaluation results of the strategy show good results. And the proposed strategy of PV charging station has certain advantages.
\end{abstract}

\section{Introduction}

Reasonable and effective pricing is the basis for smooth and orderly operation of photovoltaic users. This paper considers a microgrid electricity trading mechanism. Under the trading mechanism, the charging station serves as a guide for the market and independently makes decisions on the sale of electricity and charging rates when considering the benefits and satisfaction of sales. Without considering the charging station equipped with the energy storage system of sufficient size and capacity, it is difficult to balance the supply and demand of energy, and operators need to trade energy with the power grid.

\subsection{Efficiency model of charging station.}

Suppose a charging station equipped with a photovoltaic device of appropriate capacity. The charging car is regarded as the load of this charging station. When the load and power generation are not equal, the control center of the charging station will trade with the large power grid.

This paper, based on the charging load and power generation is known, through the control center for each moment of decision-making, to optimize the price of electricity to achieve customer satisfaction and charging station to maximize revenue [1].

Decision-making out of electricity prices at the same time, to determine the power consumption of each moment, without considering the case of energy storage, in order to maintain the balance of energy, when the power consumption is greater than the moment of power generation, the control center will have to purchase electricity price When purchasing power from a large power grid, when the power consumption is less than the amount of power generated at that moment, the control center will feed back the surplus power to the power grid by using the electricity sales price[2].

\subsection{User Charging Efficiency Model.}

Logarithmic functions are widely used to describe the benefits [3], for the user side, the benefits of each period reflects the user's satisfaction with the charging strategy.

Obviously, the more you charge in this time period, the better the user experience.

$$
\text { Pro }_{1}=\mathrm{K}_{\mathrm{n}} \cdot \ln \mathrm{E}_{\text {charge }}
$$

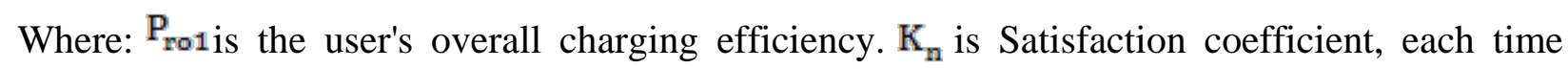


according to the needs of users will have different values.

In the process of adjusting the charging power needs to be kept to meet the basic needs of users, while not exceeding the upper limit of charging power, that is $E_{\min }<E_{\text {chaege }}<E_{\max }$.

\subsection{Charge Feasible Domain Model.}

During the charging process of an electric vehicle, the relationship between the SOC and the charging current can be expressed as [4]:

$$
\operatorname{sOC}(t)=\operatorname{SOC}\left(t_{0}\right)+\frac{I(t)}{Q^{n}}\left(t-t_{0}\right)
$$

Where: SOC $(\mathrm{t})$ is the SOC value of the electric vehicle at the moment $\mathrm{t}$. I(t) is the charging current of the electric vehicle at the moment $t$. Qn is the rated capacity of the electric vehicle. The charging rate of the electric vehicle at this moment can be expressed as:

$$
\mathrm{C}(\mathrm{t})=\frac{\mathrm{I}(\mathrm{t})}{\mathrm{Qn}}
$$

Therefore, Eq.1 can be expressed as:

$$
\operatorname{soc}(\mathrm{t})=\operatorname{soc}\left(\mathrm{t}_{0}\right)+\mathrm{C}(\mathrm{t})\left(\mathrm{t}-\mathrm{t}_{0}\right)
$$

Then the car's charging power can be expressed as:

$$
\mathrm{P}(\mathrm{t})=\mathrm{Un} \cdot \mathrm{Qn} \cdot \mathrm{C}(\mathrm{t}) \quad \mathrm{C}(\mathrm{t}) \in[\mathrm{Cmin}, \mathrm{Cmax}]
$$

Where: ${ }^{\mathrm{Un}}$ is the rated charging voltage of the charging car, $\mathrm{Cmin}, \mathrm{Cmax}$ is respectively the upper limit and lower limit of the charging power.

When the charging car arrives, the user will leave time, the target power as a message sent to the control center. Therefore, the control center can make the best decision based on this information.

At the beginning of each time period $\mathrm{T}$, the control center will update the car's battery power:

$$
\operatorname{SOC}_{\mathrm{d}}^{\mathrm{j}}=\operatorname{SOC}_{\mathrm{abj}}^{\mathrm{j}}-\operatorname{SOC}^{\mathrm{j}}(\mathrm{T}-1) \quad \mathrm{j}=1,2, \cdots, \mathrm{n}
$$

Where: ${ }^{S O c_{d}^{j}}$ is the electric quantity needed to be charged of jth car at the time $T$, ${ }^{\mathrm{j}} \mathrm{C}_{\mathrm{obj}}^{\mathrm{j}}$ is the target electric quantity of the car $\mathrm{j}$. According to the electric power needed by the car and maximum charging time, vehicles can be divided into two categories: Rigid vehicles: must be charged at time ${ }^{\mathrm{T}}$, otherwise can not reach the target power when leaving. Flexible vehicles: the charging rate at $\mathrm{T}$ moment is random, and the target power can still be reached when leaving. According to the division of the above vehicles, the upper limit $\mathrm{E}_{\max }$ of the charging power in the time period $\mathrm{T}$ is to satisfy the charging needs of all vehicles:

$$
\begin{array}{r}
\mathrm{E}_{\max }(\mathrm{T})=\sum_{\mathrm{i} \in \mathrm{D}} \min \left(\operatorname{SOC}_{\mathrm{d}}^{\mathrm{i}}, \mathrm{C}_{\max } \cdot \Delta \mathrm{T}\right) \cdot \mathrm{Q}_{\mathrm{n}}^{\mathrm{i}} \cdot \mathrm{U}_{\mathrm{n}} \\
+\sum_{\mathrm{i} \in \mathrm{M}} \min \left(\mathrm{SOC}_{\mathrm{d},}^{\mathrm{i}} \mathrm{C}_{\max } \cdot\left[\mathrm{t}_{\mathrm{dep}}^{\mathrm{i}}-(\mathrm{T}-1)\right]\right) \cdot \mathrm{Q}_{\mathrm{n}}^{\mathrm{i}} \cdot \mathrm{U}_{\mathrm{n}}
\end{array}
$$

Where: $\mathrm{D}$ is the set of cars of the second kind, $\mathrm{M}$ is the set of the cars of the first kind, ${ }^{\mathrm{i}} \mathrm{dep}$ is the time when the ith car leaves, and $\Delta \mathrm{T}$ is the duration of the time period $\mathrm{T}$.

For the lower limit of the charging power in the period $\mathrm{T}$, the charging power only needs to meet the charging requirement of the rigid vehicle, and for the flexible vehicle, the charging power of the vehicle may be selected to be 0 :

$$
\mathrm{E}_{\min }(\mathrm{T})=\sum_{\mathrm{i} \in \mathrm{M}} \min \left(\operatorname{SOC}_{\mathrm{d}}^{\mathrm{i}}, \mathrm{C}_{\max } \cdot\left[\mathrm{t}_{\mathrm{dep}}^{\mathrm{i}}-(\mathrm{T}-1)\right]\right) \cdot \mathrm{Q}_{\mathrm{n}}^{\mathrm{i}} \cdot \mathrm{U}_{\mathrm{n}}
$$




\subsection{Control Center revenue model.}

When the charging power $E_{\text {charge }}$ within the time period $\mathrm{T}$ is determined, the car is charged at a constant rate, then the revenue from charging is:

$$
\mathrm{PrO}_{2}=P_{c} \cdot E_{\text {charge }}
$$

Regardless of the energy storage situation, the energy balance must be ensured, the remaining or lack of energy after charging need to deal with the power grid, When $E_{\text {charge }}>P V$, we need to purchase the lack of electricity from the grid, When $E_{\text {charge }}<P V$, need to sell excess electricity to the grid, the proceeds of this part of the transaction with the grid are:

$$
\text { Pro }_{3}= \begin{cases}\left(P V-E_{\text {charge }}\right) \lambda_{\text {buy }} & \left(E_{\text {charge }}>P V\right) \\ \left(P V-E_{\text {charge }}\right) \lambda_{\text {sell }} & \left(P V>E_{\text {charge }}\right)\end{cases}
$$

Where: $P V$ is the photovoltaic power generation during the time period, ${ }^{\lambda_{b u y}}$ is the purchase price of electricity purchased from the grid, $\lambda_{\text {sen }}$ is the price of the electricity sold to the grid.

When the control center and the grid have energy exchange, there will be energy loss on the transmission line connecting the two. This part of energy is mainly caused by the thermal effect of the current,

Assuming that the voltage is constant, the transmitted power is approximately proportional to the current, and the power loss is proportional to the square of the current. This part of the benefit of the line loss can be expressed as ${ }^{[5]}$ :

$$
\text { Pro }_{4}=-\beta_{i} p_{i}^{2}=-\beta_{i}\left(P V-E_{\text {charge }}\right)^{2}
$$

Where: $\beta_{i}$ is defined as the loss rate at each moment, the product of the loss rate and the square of the exchange energy is the loss benefit. In summary, the charging station efficiency that comprehensively considers user satisfaction and charging station revenue is as follows:

$$
\begin{gathered}
\text { Pro }=\sum_{j=1}^{4} \text { Pro }_{\mathrm{j}}= \\
\left\{\begin{array}{cc}
K_{n} \cdot \ln E_{\text {charge }}+P_{c} \cdot E_{\text {charge }}+\left(P V-E_{\text {charge }}\right) \lambda_{\text {buy }}-\beta_{i} p_{i}^{2} & \left(E_{\text {charge }}>P V\right) \\
K_{n} \cdot \ln E_{\text {charge }}+P_{c} \cdot E_{\text {charge }}+\left(P V-E_{\text {charge }}\right) \lambda_{\text {sell }}-\beta_{i} p_{i}^{2} & \left(P V>E_{\text {charge }}\right)
\end{array}\right.
\end{gathered}
$$

In fact, $P_{c}$ and $E_{\text {charge }}$ are not two independent variables, the data of the previous time-share price are interpolated, $P_{c}$ and $E_{\text {charge }}$ approximate the relationship between inverse function, the higher the charging price of a period of time, apparently the less vehicles that are chosen to be charged during this time period, the lower the charging power, the relationship between the two can be expressed as:

$$
E_{\text {charge }}=\frac{k_{p}}{P_{c}}
$$

Where: $k_{p}$ can be defined as the conversion coefficient between charging power and charging price.

Then Eq.2 can be expressed as: 


$$
\begin{array}{r}
\text { Pro }=\sum_{j=1}^{4} \text { Pro }_{\mathrm{j}}= \begin{cases}K_{n} \cdot \ln E_{\text {charge }}+k_{p}+\left(P V-E_{\text {charge }}\right) \lambda_{\text {buy }}-\beta_{i} p_{i}^{2} & \left(E_{\text {charge }}>P V\right) \\
K_{n} \cdot \ln E_{\text {charge }}+k_{p}+\left(P V-E_{\text {charge }}\right) \lambda_{\text {sell }}-\beta_{i} p_{i}^{2} & \left(P V>E_{\text {charge }}\right)\end{cases} \\
= \begin{cases}K_{n} \cdot \ln E_{\text {charge }}+k_{p}+\left(P V-E_{\text {charge }}\right) \lambda_{\text {buy }}-\beta_{i}\left(P V-E_{\text {charge }}\right)^{2} & \left(E_{\text {charge }}>P V\right) \\
K_{n} \cdot \ln E_{\text {charge }}+k_{p}+\left(P V-E_{\text {charge }}\right) \lambda_{\text {sell }}-\beta_{i}\left(P V-E_{\text {charge }}\right)^{2} & \left(P V>E_{\text {charge }}\right)\end{cases}
\end{array}
$$

In order to get the maximum return at a time corresponding to the charging power, the formula can be derived:

$$
\mathrm{Pro}^{\prime}= \begin{cases}\frac{K_{n}}{E_{\text {charge }}}-\lambda_{\text {buy }}+2 \beta_{i}\left(P V-E_{\text {charge }}\right) & \left(E_{\text {charge }}>P V\right) \\ \frac{K_{n}}{E_{\text {charge }}}-\lambda_{\text {sell }}+2 \beta_{i}\left(P V-E_{\text {charge }}\right) & \left(P V>E_{\text {charge }}\right)\end{cases}
$$

Let the derivative be 0 to get the optimal charging power:

$$
E_{\text {charge }}= \begin{cases}\frac{2 \beta_{i} \cdot P V-\lambda_{\text {buy }} \mp \sqrt{\left(\lambda_{\text {buy }}-2 \beta_{i} \cdot P V\right)^{2}+8 \beta_{i} K_{n}}}{4 \beta_{i}} & \left(E_{\text {charge }}>P V\right) \\ \frac{2 \beta_{i} \cdot P V-\lambda_{\text {sell }} \mp \sqrt{\left(\lambda_{\text {sell }}-2 \beta_{i} \cdot P V\right)^{2}+8 \beta_{i} K_{n}}}{4 \beta_{i}} & \left(P V>E_{\text {charge }}\right)\end{cases}
$$

For the above two cases, the choice of charging power should comply with the following inequality constraints:

$$
\left\{\begin{array}{c}
E_{\min } \leq E_{\text {charge }} \leq E_{\max } \\
P_{c} \leq P_{0} \\
\min P_{c}
\end{array}\right.
$$

Where, $P_{0}$ is the original charging price, the optimized price should not be higher than this.

\subsection{Charging Power Distribution.}

After getting the optimal power of each time period, it should be assigned to each charging car according to a certain rule. After the time period T is determined, the information of the vehicle is determined. The optimal charging power calculated in this period of time is $E_{\text {charge }}(\mathrm{T})$, the charging strategy is as follows ${ }^{[6]}$ :

Step1: For a rigid charging car, set $C^{i}(T)=C_{\max }^{i}(T)$; for a flexible charging car, set $C^{i}(T)=C_{\min }^{i}(T)$;

Step2: Calculate the current power consumed by all charging cars:

$$
P^{k}(T)=\sum_{i \in D, M} C^{i}(T) \cdot U_{n} \cdot Q_{n}
$$

Step3: if $P^{k}(T)<E_{\text {charge }}(\mathrm{T})$, increase the charging rate of flexible cars until

$$
\begin{gathered}
P^{k}(T)=E_{\text {charge }}(\mathrm{T}): \\
C^{i}(T)=C^{i}(T)+\varepsilon \cdot C_{\max }^{i}(T) \quad i \in D, C^{i}(T)<C_{\max }^{i}(T)
\end{gathered}
$$

Where, $\varepsilon$ is the step of rate's increase.

\section{The Practical Example.}

Photovoltaic output: 


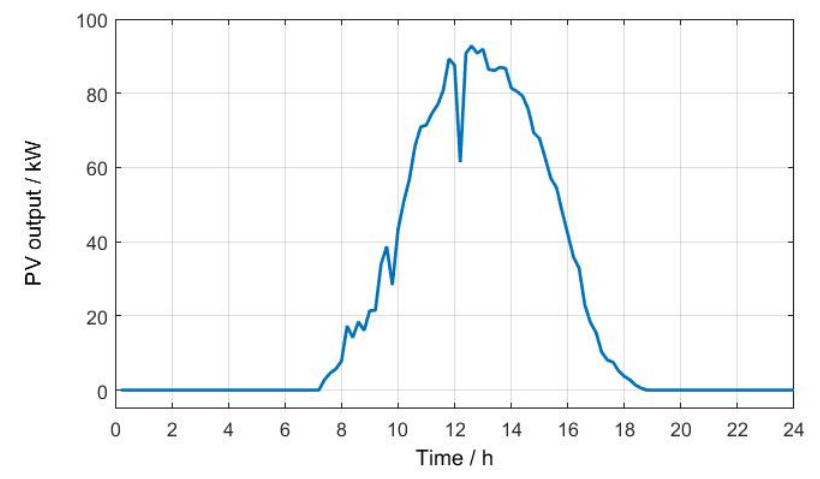

Fig. 1 Photovoltaic output

Charging power:

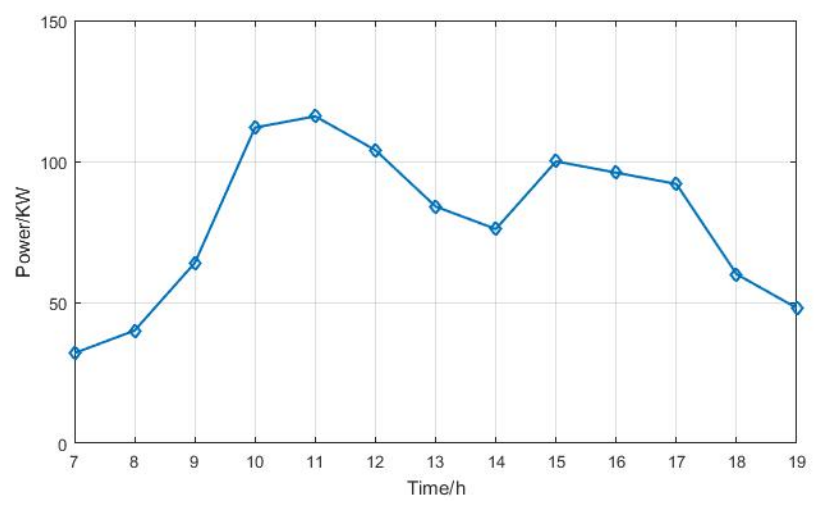

Fig. 2 Charging power

Line load:

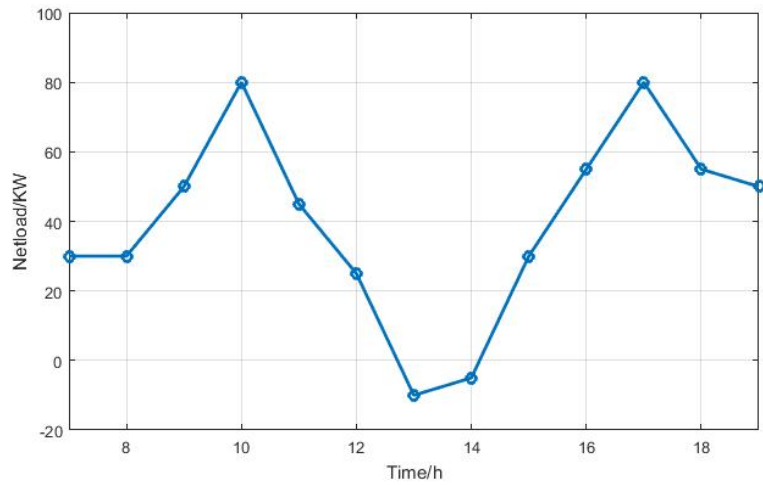

Fig. 3 Line load

Optimization of Electrovalence:

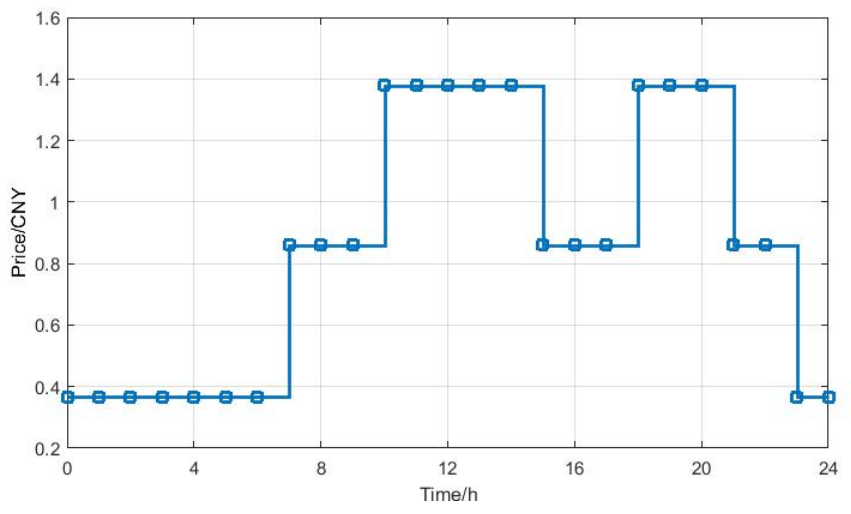

Fig. 4 Optimization of Electrovalence 
The charging rate:

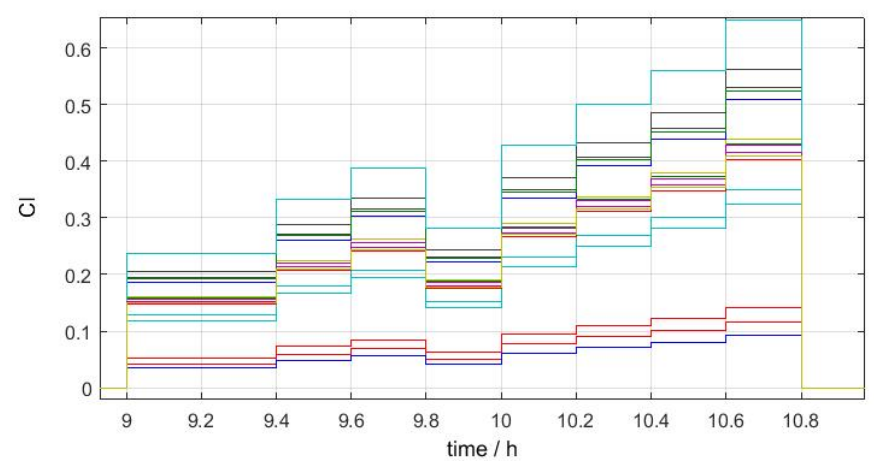

Fig. 5 The charging rate

Efficiency of charging station:

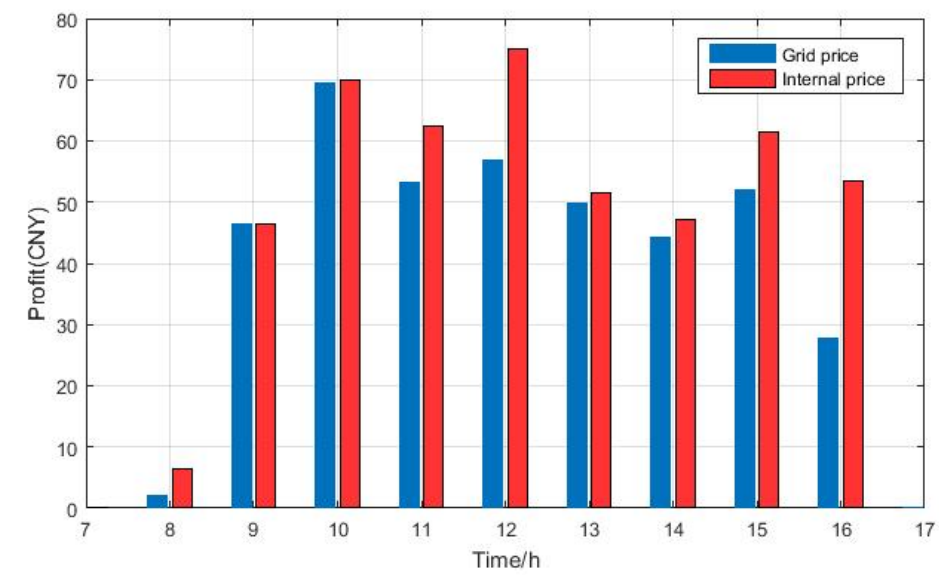

Fig. 6 Efficiency of charging station

\section{Analytic Hierarchy Process}

Establish a system to evaluate the operating efficiency of PV charging stations.

\subsection{The principle of Analytic Hierarchy Process.}

The basic idea of AHP to solve the problem is to arrange the subordinate relations between the various factors of the system in descending order and to establish the interrelationship between elements at different levels. Based on the judgment of a certain objective reality, it determines the relative importance of each level, and uses mathematical methods to determine the weight of the relative importance order of all elements at each level to analyze and make decisions[7].

\subsection{Electric vehicle charging station energy efficiency evaluation index system.}

Based on the expert's knowledge and experience, this dissertation establishes the evaluation index system for the operating benefit of EV charging station. The system includes a target layer that is the evaluation of the operation efficiency of PV charging stations, and the four guideline layers are economic, environmental, reliability and user convenience as well as the eight indicators of the factor layer.

\section{Evaluation of the Operating Benefit of Electric Vehicle Charging Station}

Fuzzy Comprehensive Evaluation.

Fuzzy comprehensive evaluation is based on fuzzy mathematics, applying the principle of fuzzy relational synthesis, quantifying some unclear factors and finally conducting a comprehensive 
evaluation.In this paper,we use fuzzy comprehensive evaluation method to achieve the evaluation of the operating efficiency of electric vehicle charging station[8].

(1) Determine the set of factors for the evaluation object

We have $P$ evaluation indicators, $u=\left\{u_{1}, u_{2}, \cdots \cdots, u_{p}\right\}$.

(2) Determine the rating level set $v=\left\{v_{1}, v_{2}, \cdots \cdots, v_{p}\right\}$.Each level can correspond to a fuzzy subset.Each level can correspond to a fuzzy subset, as well as a standard membership set. $J=\left(J_{1}, J_{2}, \cdots \cdots, J_{m}\right), J=\{5$ (excellent),4( great),3( good ),2( pass ),1(failed ) .

(3) Establish fuzzy relation matrix $R=\left(r_{i j}\right)_{m \times n}$.

(4)According to the analytic hierarchy process to determine the weight vector of evaluation factors: $A=\left(a_{1}, a_{2}, \cdots \cdots, a_{p}\right)$.

(5) Choose a synthesis operator: $B^{\prime}=A R$

(6) The weights of the elements in the evaluation vector $B=\left(b_{1}, b_{2}, \cdots \cdots, b_{m}\right)$ are normalized, and the total scores are obtained by averaging the scores of the respective rating levels:

$$
G=\frac{\sum_{i=1}^{m} b_{i} J_{i}}{\sum_{i=1}^{m} b_{i}}
$$

In order to get the result of scientific evaluation, the fuzzy math language is used to make the comment fuzzy, and the level of evaluation index is quantified as shown in Table 1.

Table 1

\begin{tabular}{|c|c|c|c|c|}
\hline \multicolumn{2}{|c|}{ Tier 2 indicators } & \multicolumn{3}{|c|}{ Tier 3 indicators } \\
\hline indicator & The weight of & indicator & Relative & The weight of \\
\hline \multirow{3}{*}{ B1 } & \multirow{3}{*}{0.438} & $\mathrm{C} 1$ & 0.425 & 0.186 \\
\hline & & $\mathrm{C} 2$ & 0.313 & 0.137 \\
\hline & & C3 & 0.262 & 0.115 \\
\hline \multirow[t]{2}{*}{ B2 } & \multirow[t]{2}{*}{0.181} & C4 & 1.000 & 0.181 \\
\hline & & C5 & 0.318 & 0.072 \\
\hline \multirow[t]{2}{*}{ B3 } & \multirow[t]{2}{*}{0.227} & C6 & 0.296 & 0.067 \\
\hline & & C7 & 0.386 & 0.088 \\
\hline B4 & 0.154 & C8 & 1.000 & 0.154 \\
\hline
\end{tabular}

According to the requirements of analytic hierarchy process, the consistency of each judgment matrix is tested, and the results are consistent with the requirements of consistency. After determining the set of factors and evaluation rating of the object to be evaluated, the fuzzy relation matrix $R$ is constructed according to the scoring of experts.

$$
R=\left[\begin{array}{lllll}
0.183 & 0.426 & 0.246 & 0.124 & 0.022 \\
0.113 & 0.269 & 0.225 & 0.340 & 0.053 \\
0.538 & 0.404 & 0.058 & 0.000 & 0.000 \\
0.187 & 0.292 & 0.358 & 0.097 & 0.073
\end{array}\right]
$$

Table 2 shows the weight of the second level indicator matrix A, according to:

$$
B^{\prime}=A R
$$

Calculated, normalized to give:

$$
B=\left[\begin{array}{llll}
0.3289 & 0.2431 & 0.3175 & 0.1105
\end{array}\right]
$$


According to:

$$
G=\frac{\sum_{i=1}^{\mathrm{m}} b_{i} J_{i}}{\sum_{i=1}^{m} b_{i}}
$$

Get the total score $G=4.238$, according to table 2 .

Table 2

\begin{tabular}{llllll}
\hline Standard & excellent & great & good & pass & failed \\
\hline Score & {$[4.5-5.0]$} & {$[3.5-4.5]$} & {$[2.5-3.5]$} & {$[1.5-2.5]$} & {$[1.0-1.5]$} \\
\hline
\end{tabular}

We can see that the charging station energy efficiency rating is great.

\section{References}

[1] Van Roy, J.; Leemput, N.; Geth, F.; Salenbien, R. Apartment Building Electricity System Impact of Operational Electric Vehicle Charging Strategies[J]. IEEE Trans. Sustain. Energy 2014, 5, 264-272.

[2] N Liu, Z Chen, J Liu, X Tang, X Xiao and J Zhang. Multi-objective optimization for component capacity of the photovoltaic-based battery switch stations: Towards benefits of economy and environment[J]. Energy 2014, 64, 779-792.

[3] Dusit Niyato,Ekra Hossain,Zhu Han.Dynamics of multiple-seller and multiple-buyer spectrum trading in cognitive radio networks: a game-theoretic modeling approach[J] .IEEE Transactions on Mobile Computing, 2009,8(8):1009-1022.

[4] S Tian, B Wang and J Zhang.Key technologies for demand response in smart grid[J].Proceedings of the CSEE,2014,34(22):3576-3589.(In Chinese)

[5] C Zhao, J He and P Cheng. Consensus-Based Energy Management in Smart Grid With Transmission Losses and Directed Communication[J]. IEEE Transactions on Smart Grid, 2017, 8 (5): 2049-2061.

[6] N Liu, Q Chen, J Liu, X Lu, P Li, J Lei and J Zhang. A Heuristic Operation Strategy for Commercial Building Microgrids Containing EVs and PV System[J]. IEEE Trans. Ind. Electron. 2015, 62, 2560-2570.

[7] J Guo, Z Zhang and Q Sun. Study and Applications of Analytic Hierarchy Process[J]. China Safety Science Journal, 2008, 18(5):148-153. (In Chinese)

[8] Jin Juliang, Wei Yiming, Ding Jing. Fuzzy comprehensive evaluation model based on improved analytic hierarchy process[J]. Journal of Hydraulic Engineering, 2004, 35(3):65-70. (In Chinese) 